\title{
Measuring institutional overlap in global governance
}

\author{
Yoram Z. Haftel ${ }^{1}$ (D) Tobias Lenz $^{2}$
}

Accepted: 5 February 2021/ Published online: 29 March 2021

(C) The Author(s) 2021

\begin{abstract}
Over the past decade, an increasingly sophisticated literature has sought to capture the nature, sources, and consequences of a novel empirical phenomenon in world politics: the growing complexity of global governance. However, this literature has paid only limited attention to questions of measurement, which is a prerequisite for a more comprehensive understanding of global governance complexity across space and time. In taking a first step in this direction, we make two contributions in the article. First, we propose new quantitative measures that gauge the extent of complexity in global governance, which we conceptualize as the degree to which global governance institutions overlap. Dyadic, weighted, directed-dyadic, and monadic measures enable a multifaceted understanding of this important development in world politics. Second, we illustrate these measures by applying them to an updated version of the most comprehensive data set on the design of intergovernmental organizations (IGOs): the Measure of International Authority (MIA). This allows us to identify cross-sectional and temporal patterns in the extent to which important IGOs, which tend to form the core of sprawling regime complexes in many issue areas, overlap. We conclude by outlining notable implications for, and potential applications of, our measures for research on institutional design and evolution, legitimacy, and legitimation, as well as effectiveness and performance. This discussion underscores the utility of the proposed measures, as both dependent and independent variables, to researchers examining the sources and consequences of institutional overlap in global governance and beyond.
\end{abstract}

Keywords Regime complexity · Global governance $\cdot$ International organizations · Overlap

\footnotetext{
The order of authors is chosen alphabetically. Author contributions to writing and conceptual development: Y.H. (50\%), T.L. (50\%); measurement and empirical analysis: Y.H. (80\%), T.L. (20\%); theoretical implications: Y.H. (20\%), T.L. (80\%). Research for this article was generously supported by the Ministry of Science and Culture of Lower Saxony's Research Cooperation Lower Saxony - Israel grant. We thank Mette Eilstrup-Sangiovanni, Benjamin Faude, Stephanie Hofmann, Oliver Westerwinter, Michael Zürn, the participants at a panel of the German Political Science Association International Relations Section conference, Freiburg, October 2020, and the anonymous reviewers for helpful comments and suggestions. A special thanks is due to Liesbet Hooghe who proposed the idea of writing a measurement article on institutional overlap. We also thank Dan Eran and Mona Saleh for valuable research assistance.
} 


\section{Introduction}

International relations research is increasingly addressing questions relating to the complexity of global governance, which has grown enormously since the end of the Second World War and has diversified in institutional form. Whereas the post-War international order was centrally based on a few well-ordered intergovernmental organizations (IGOs) and treaties - the United Nations (UN), the International Monetary Fund, the World Bank (WB), and the General Agreement on Tariffs and Trade (GATT) - today's global governance architecture consists of a variety of formal and informal, regional, and global IGOs, self-standing international treaties, transgovernmental networks, non-governmental organizations, and transnational publicprivate partnerships. This multiplication and diversification of international institutions has resulted in a much denser global governance space.

This development is significant because the dynamics of global governance are fundamentally different when they occur in a dense institutional space than in a 'wellordered' international system. Under these conditions, the likelihood of overlap and interplay between elemental institutions increases, with three primary repercussions. First, complexity generates ambiguities and potential 'legal inconsistencies' between the norms and rules of different institutions (Raustiala and Victor 2004: 280; see also Alter and Sophie Meunier 2009), which may hamper compliance by those to whom the rules apply. Second, complexity blurs the lines of responsibility for action and outcomes and increases the likelihood of unintended consequences (Pierson 1996). This places a burden on member states to control governance processes and makes it difficult to hold relevant actors accountable, and both of these hindrances may undermine the legitimacy of global governance arrangements. Third, complexity opens up new strategic opportunities for governance actors: they may shift between institutions as their strategic priorities change (Alter and Sophie Meunier 2009; Morse and Keohane 2014; Verdier 2021). As previous focal institutions are rivalled, the effectiveness of global governance may diminish while the status quo bias of institutional arrangements is reduced (Faude and Abbott 2020). ${ }^{1}$ Overall, growing institutional complexity has the potential to undermine the effectiveness and legitimacy of always-fragile efforts to advance international cooperation.

Systematic explorations of institutional complexity in global governance require a comprehensive picture of the phenomenon under study. How extensive is it? How does it vary across organizations, issue areas, and parts of the world? How has it evolved over time? Surprisingly, scholars have focused most of their attention on conceptualizing the phenomenon and discussing its sources and consequences, drawing on a small number of cases, rather than on gauging the extent of the phenomenon itself. Hence, our empirical knowledge of the institutional complexity of global governance remains limited.

Some scholars have started mapping the institutional complexes in individual issue areas, such as plant genetic resources (Raustiala and Victor 2004), climate change (Abbott 2012; Keohane and Victor 2011), trade (Brosig 2011; Davis 2009; Gómez-

\footnotetext{
${ }^{1}$ This is not to deny that there are second-order effects of institutional density that may trigger a 're-ordering' of complexes and more cooperative relations subsequently (see Eilstrup-Sangiovanni 2021; Gehring and Faude 2014; Abbott and Faude 2021).
} 
Mera 2015), intellectual property rights (Helfer 2004), international civil aviation (Eilstrup-Sangiovanni 2021), refugee protection (Betts 2010), human trafficking (Gómez-Mera 2015), finance (Henning 2017), and security (Hofmann 2009). However, these analyses tend to be rich qualitative descriptions that do not rest on a generic measure suitable for applications across issue areas and geographical regions, and also commonly provide snapshot pictures that neglect the evolution of complexity over time. Other scholars have focused on specific institutional types, such as technical assistance providers in intellectual property (Morin 2020), regional organizations (Haftel and Hofmann 2019; Panke and Stapel 2018), or multi-stakeholder initiatives in international development (Reinsberg and Westerwinter 2019; Westerwinter 2021). What is missing, however, is systematic knowledge of institutional complexity, and achieving this knowledge requires paying closer attention to questions of measurement.

Our article makes three contributions to this research agenda. First, following Eilstrup-Sangiovanni and Westerwinter's (2020) call, we propose new, quantitative measures of institutional complexity in global governance, which we conceptualize as overlap between global governance institutions. The first, 'baseline' measure gauges the overlap between institutional pairs, calculated on the basis of their overlap in membership and the policy areas in which they have competency. The second measure begins with the baseline measure but takes into account the centrality of an institution's policy competencies to its activity. A third, directed-dyadic measure affords insights into potential imbalances in overlap between two institutions that are unequal in terms of membership and policy competency. Finally, we use this directed-dyadic measure to calculate a monadic measure that allows us to gauge the degree of overlap of a specific institution with two or more additional institutions. This variable serves as a proxy for the interaction potential between an individual institution within, for example, an issuespecific governance complex or a geographically demarcated complex. These different measures are applicable to a broad set of governance institutions and can be used by scholars studying these phenomena. ${ }^{2}$ They allow scholars to systematically capture the potential for the aforementioned problems of global governance complexity to emerge, and to study the sources and consequences of this empirical phenomenon.

Second, we identify cross-sectional and temporal patterns in the complexity of a particular type of global governance institution - formal IGOs - by applying our measures to an updated version of the Measure of International Authority (MIA) (Hooghe et al. 2017), ${ }^{3}$ the most comprehensive and detailed dataset of this institutional form currently available. We find that IGO overlap, in general, has roughly doubled from 1970 until today, and that this process was driven mostly by the expansion of IGOs' policy competencies rather than by membership. Drawing on the distinction between general purpose and task specific IGOs (Lenz et al. 2015), we also show that the degree of overlap between task specific IGOs tends to be bimodal (that is, either high or low). Overlap values for general purpose IGOs, on the other hand, are distributed more evenly along the continuum. These observations mark a first step

\footnotetext{
${ }^{2}$ Panke and Stapel (2018) developed a measure similar to our dyadic one, with the exception that they did not normalize the number of overlapping members and policy competencies with respect to the total number of these variables (see below). In addition, they did not consider the weighted, directed dyadic, and monadic measures constructed here and their empirical analysis focused on a smaller sample of regional IGOs.

${ }^{3}$ Unless noted otherwise, we use the term IGO as a shorthand for a formal IGO.
} 
towards a more systematic understanding of institutional complexity at the heart of global governance.

Third, we discuss the implications and potential applications of the analysis for ongoing debates on institutional design and evolution, legitimacy and legitimation, and effectiveness and performance - three key aspects of state-of-the-art research on international institutions. We show that a more comprehensive picture of institutional complexity in global governance raises new questions about the sources and consequences of this phenomenon and points towards exciting new avenues for theorizing and empirical inquiry. In examining these issues, our measures can serve both as dependent and independent variables.

We focus on formal IGOs because such institutions constitute the core of global governance in most issue areas. As Raustiala and Victor (2004: 278) observed, most regimes are "centred on a core international agreement and administered by a discrete organization", generally a formal IGO. The WTO is not just any institution in the governance complex for international trade, but its focal institution (Davis 2009). The same holds for the WB in international development finance, or the UN in international security. Similarly, continental IGOs often serve as focal institutions for regional governance complexes, as is the case with the African Union (AU) in Africa or the Organization of American States (OAS) in the Americas.

Unlike other institutions in global governance, IGOs create binding commitments for states that are, to varying degrees, enforceable through international (and sometimes domestic) legal mechanisms (Abbott et al. 2000). Moreover, they commonly influence the agenda setting and framing of international problems in ways that are unrivalled by other institutions (Barnett and Finnemore 2004; Knill et al. 2019). This is the case not only because IGOs create binding commitments and are often the most well-endowed actors in global governance complexes (besides powerful states, of course), but also because they regularly orchestrate other actors in the governance of transnational problems. In so doing, they are pivotal in the very "emergence and diffusion of regime complexes" (Abbott et al. 2015: 7).

As a result, overlap between different IGOs is likely to be consequential in its own right, and also for governance complexes as a whole. By generating the conditions for rule conflict, for blurring lines of accountability, and for cross-institutional strategies, institutional overlap is likely to affect international cooperation, and the stakes are particularly high when the core of governance complexes - formal IGOs - is concerned. Unsurprisingly, much of the literature on the consequences of governance complexity has focused on this institutional type (see, for example, Betts 2013; Lesage and Van de Graaf 2013; Pratt 2018). Given their central role in global governance, the absence of systematic empirical information about IGO complexity constitutes a serious gap in extant research.

We acknowledge that the empirical focus on a subset of existing IGOs overlooks additional institutions that, to varying degrees, make up most international governance complexes. Therefore, our measures probably underestimate governance complexity, as we explain in greater detail below. In this respect, the goal of the empirical analysis is to illustrate our approach rather than to draw firm conclusions about the actual complexity of global governance. Given that the proposed measures can be applied to all types of international institutions, rather than just IGOs, we believe that they offer solid foundations for further empirical research on global governance complexity.

The article proceeds as follows. In the next section, we conceptualize complexity in global governance and then introduce our quantitative measures of institutional overlap. 
In the third section we operationalize the various components of these measures and present several empirical trends. The fourth section considers the theoretical implications of our descriptive findings and possible applications of the measures developed in this study for institutional design, legitimacy, and performance. The final section concludes.

\section{Conceptualizing and measuring institutional overlap in global governance}

\subsection{Conceptualization}

The notion of institutional overlap is central to any understanding of governance complexity. In their agenda-setting piece, Raustiala and Victor (2004: 279) defined what they term a regime complex as a "an array of partially overlapping and nonhierarchical institutions governing a particular issue area." In another influential contribution, Orsini et al. (2013: 29) defined a regime complex as "a network of three or more international regimes that relate to a common subject matter; exhibit overlapping membership; and generate substantive, normative, or operative interactions recognized as potentially problematic whether or not they are managed effectively." A recent overview uses the following definition: "A regime complex is an array of partially overlapping and non-hierarchical institutions that includes more than one international agreement or authority" (Alter and Raustiala 2018: 332). Eilstrup-Sangiovanni and Westerwinter (2020) used the notion of global governance complex, which they define as "a system of governance composed of at least three international or transnational institutions or actors whose missions, functions, and membership overlap, and that jointly address a specific policy problem."

While these definitions differ in several important respects, ${ }^{4}$ they share a common conceptual core: institutional complexity captures a situation in which the claims to govern a particular policy area overlap among two or more global governance institutions. In other words, governance complexes are systems in which member states or private actors have endowed overlapping international institutions with a legitimate claim to govern a particular policy area in world politics.

This implies that there are two elements of institutional overlap, both of which are necessary and jointly sufficient: overlap in policy competency and overlap in membership. The former means that two institutions govern the same policy area, whether it is the liberalization of trade, the maintenance of international peace and security, or environmental protection. For example, the WTO and the Common Market of the South (Mercosur) overlap in policy competency (trade liberalization), as do the UN and the AU (international peace and security). Overlapping membership denotes a situation in which the same states (or other actors) are members in two or more institutions. For example, the Council of Europe (CoE) and the European Union (EU) share large parts of their membership, as do the OAS and the Andean Community (ANCOM).

However, institutional overlap, with its attendant dynamics of interaction and competition, only emerges when both conditions are present simultaneously. Institutions that

\footnotetext{
${ }^{4}$ Conceptual emphasis varies, for example, with respect to the role of non-hierarchy as a defining feature of a regime complex, whether they are functionally or organizationally defined, and whether the various elements of a complex are loosely or tightly coupled.
} 
govern the same policy area, but distinct participant actors, do not overlap. For instance, the governance of trade liberalization by Mercosur in Latin America is not directly affected by the Association of Southeast Asian Nations (ASEAN) pursuing similar objectives in Asia. ${ }^{5}$ Conversely, even institutions in which large parts of the membership are identical do not affect each other's governance activities to any serious degree unless they have competence with respect to the same policy area. For example, the WTO and the Universal Postal Union (UPU) - both of which have close to universal membership coexist comfortably, without rivalling governance claims.

From this perspective, institutional overlap may result from three distinct processes: the creation of a new institution with similar policy competencies to an existing one, accession of new members to an existing institution, and policy expansion of an existing institution. The first process may be motivated by inefficiencies that cannot be remedied within the existing institution itself (Urpelainen and Van de Graaf 2014) - a situation that Morse and Keohane (2014) termed "competitive regime creation." China's initiative to create the New Development Bank (NDB) and the Asian Infrastructure and Investment Bank (AIIB) is often interpreted as such a move because China and other emerging powers failed to gain substantially more influence in the WB.

Institutional overlap may also emanate from changes in the membership of an institution. When an actor or a group of actors that are already members in an institution with a specific policy competency enter another institution with a similar competency, these actors create overlap between the two. Such a decision may be the result of the growing attractiveness of another institution with similar governance functions. For example, Bolivia, which is already a member of ANCOM, is in the process of acceding to Mercosur. Given that no state is currently a member of both IGOs, to the extent that Bolivia will become a full member of Mercosur, this organization and ANCOM will overlap in membership as well as in policy competency.

Third, institutional overlap may result from an expansion of an institution's policy competency such that it starts encroaching on that of another institution (Betts 2013). As new transnational problems arise, states regularly expand the policy competency of an existing institution to address them, rather than creating a new one (Jupille et al. 2013). Alternatively, like-minded states in a gridlocked institution may employ a different institution in which they are members in order to tackle a broader set of policies (Haftel and Hofmann 2019). An example of such a process is the expansion of the EU into the security realm with the Common Security and Defence Policy in 1993, which made it overlap with the North Atlantic Treaty Organization (NATO) (Hofmann 2019).

These sources of institutional overlap indicate that the concept is both relational and continuous. Regarding the former, overlap captures a characteristic of how different institutions relate to each other, suggesting a dyadic measurement strategy. Regarding the latter, overlap may be present or it may be absent, and there are degrees of partial overlap depending on how many member states and policy competencies overlap (see Fig. 1). In line with Eilstrup-Sangiovanni and Westerwinter (2020), this conceptualization allows us to gauge variation in the extent of overlap between institutions. The relational

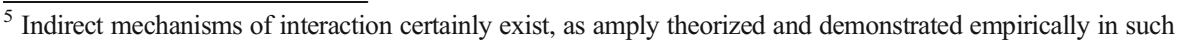
diverse processes as diffusion, market competition, and cultural evolution. In addition, institutions with different members but a similar policy competency may interact or compete in a 'non-complex' manner (for example, the rivalry between the European Economic Community and the European Free Trade Agreement in the 1960s). Such dynamics are beyond the scope of this article.
} 


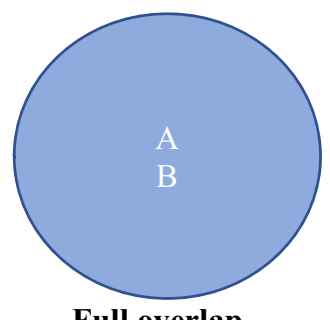

Full overlap
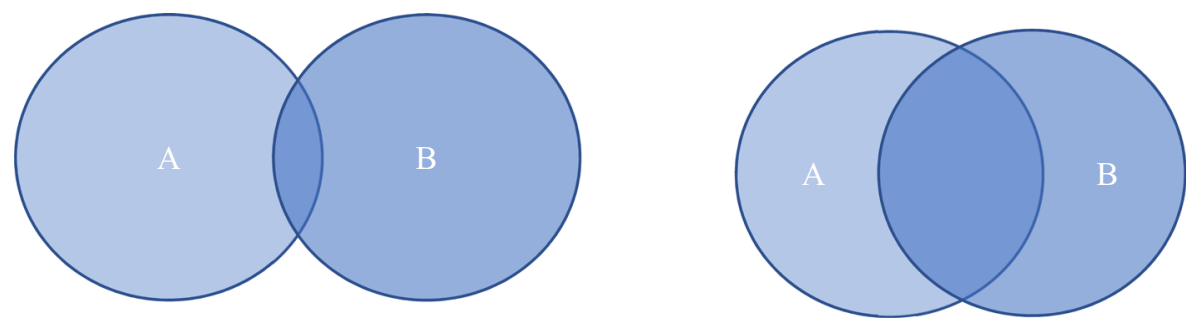

Partial overlap

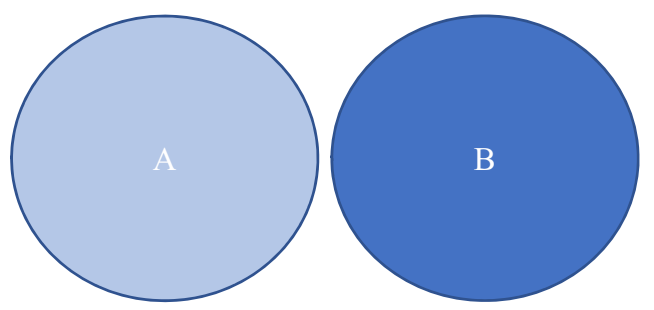

No overlap

Fig. 1 Degrees of overlap in institutional dyads

and continuous aspects of overlap are reflected in our quantitative measures, to which we now turn.

\subsection{Measurement}

We start with a 'baseline' measure that gauges the extent of overlap for pairs of international institutions. Our combined Membership and Policy Overlap Score henceforth: Dyadic MEPOS - takes into account the number of overlapping members and policy areas out of the total number for the two institutions. The measure is calculated in three steps, as follows:

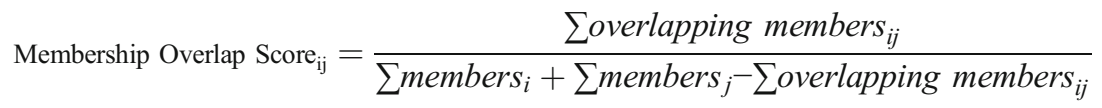




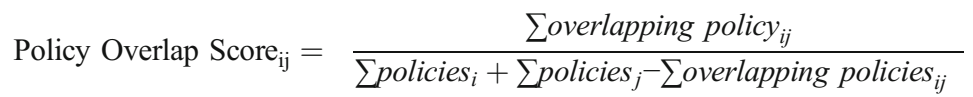

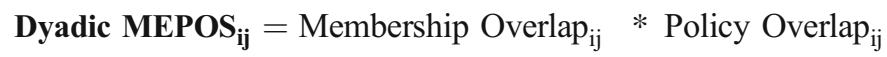

Dyadic MEPOS ranges from zero (for no overlap) to one (for identical membership and policy competency). Given that overlap in both membership and policy areas is necessary to generate complexity, our measure equals zero when either one of its two components equals zero. The Common Market of Eastern and Southern Africa (COMESA)/East African Community (EAC) dyad, taken from the sample and based on definitions of membership and policy competencies discussed in the next section, illustrates the construction of this measure. In 2010, COMESA had nineteen members and competencies in nine issue areas; EAC had five members and competencies in twenty issue areas. These regional IGOs overlapped with respect to four states and eight issue areas. Accordingly, the overlapping membership score is $4 /(19+5-4)=$ 0.20 ; the overlapping policy score is $8 /(9+20-8)=0.38$; and the value on Dyadic $M E P O S$ is $0.20 * 0.38=\mathbf{0 . 0 7 6}$.

Evidently, Dyadic MEPOS does not take into account the potential imbalance within a given institutional pair; that is, the percentage of overlapping members and policy competencies out of their total numbers, which may differ for any two institutions. This may be the case, for example, when they are not of equal size in terms of membership and competencies. Figure 2 presents an extreme case of this phenomenon. While institution B is fully nested within institution A, which means that overlap for B is complete, overlap from the perspective of A with $\mathrm{B}$ is only partial. Revisiting the COMESA/EAC example, the four states that belong to both IGOs reflect an $80 \%$ overlapping membership for EAC (out of five members), but only $21 \%$ for COMESA (out of nineteen members). The eight policy areas covered by both IGOs reflect a $40 \%$ overlap for EAC, but $89 \%$ for COMESA, out of twenty and nine policy areas, respectively.

To account for the degree of overlap for each institution in the dyad, we construct a directed measure, labelled Directed MEPOS, which is the number of overlapping

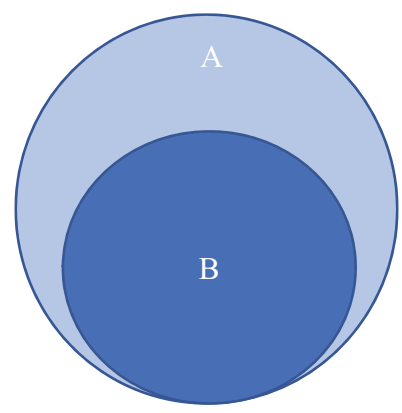

Fig. 2 Imbalanced overlap in nested institutions 
members and policy competencies in relation to the paired institution out of their total number. Thus:

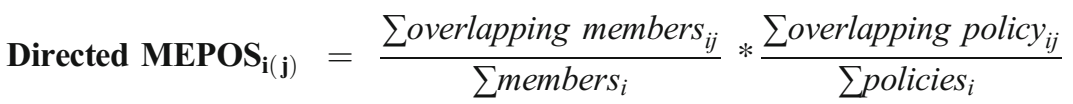

As before, the values on this measure range from zero to one. Given that the numerators remain intact, but that the denominators account only for one institution, the values on Directed MEPOS are higher than those on Dyadic MEPOS. In the 2010 COMESA/ EAC case, Directed MEPOS is about 0.19 for COMESA and 0.32 for EAC (compare with 0.076 for Dyadic MEPOS).

This directed measure of overlap has one distinct advantage over the baseline measure: it allows one to calculate an overall 'monadic' level of overlap, a variable we label Monadic MEPOS. This variable is the average Directed MEPOS vis-à-vis two or more IGOs. Thus:

Monadic MEPOS $i=\frac{\sum \text { Directed } \text { MEPOS }_{i j_{1}}, \ldots \text { Directed MEPOS }}{i j n}$

In this equation, $i$ denotes a given institution, whereas $j 1, j 2$, etc., denote other global governance institutions. This monadic variable could be calculated in relation to an entire sample of institutions, to a group of institutions that tackle the same policy competency, to global or regional institutions, and so on. For example, revisiting the two African IGOs, the Monadic MEPOS of COMESA and EAC in relation to all other African Regional Economic Organizations (REOs) included in our sample is 0.21 and 0.18 , respectively. One can think of this variable as a proxy for the interaction potential between a given institution and the rest of a particular reference group in terms of competition, collaboration, or learning. Having clarified the logic and construction of our measures, we turn next to their application on actual data.

\section{Illustrating the measures: Patterns in IGO overlap}

In this section we illustrate the three measures developed in the previous section Dyadic MEPOS, Directed MEPOS and Monadic MEPOS - and use them to gauge variation across IGOs and over time by drawing on the MIA dataset (Hooghe et al. 2017). Covering the period 1950 to 2017, MIA draws its sample from the Correlates of War dataset and identifies those IGOs that are not emanations of other IGOs and have at least a minimal level of infrastructure (Hooghe et al. 2017: 16). The seventy-six IGOs in the sample are the most authoritative IGOs that have existed in world politics in the post-Second World War era (see Appendix A for a full list). As discussed in the introduction, we believe that it makes sense to start a systematic inquiry into the complexity of global governance by analyzing the core of governance complexes with the largest available sample of relatively authoritative IGOs around the world. 
Two other components of our measure require operationalization. Regarding membership, we follow conventional operationalizations that gauge the number of states that are full members in a specific IGO. We use the Correlates of War IGO Version 3.0 dataset for data on IGO membership (Pevehouse et al. 2020). This dataset includes membership information up to 2014, thereby bounding the empirical analysis to that year. To operationalize policy competency, we rely on Hooghe et al. (2019), who identified twenty-five policy areas listed in Appendix $\mathrm{B}$, and determined whether a given IGO has competency in each of them in a given year, based on eight legal, financial, and organizational indicators. We also follow Hooghe et al.'s distinction between 'core' competencies, which require the presence of at least three such indicators, and 'flanking' ones, which indicate the presence of only one or two indicators. Based on the purposes that an IGO pursues, they further differentiate between 'general purpose' and 'task specific' organizations; the former type tends to revolve around a given transnational community and the latter type often addresses only a small number of issues (Lenz et al. 2015).

Four caveats related to our reliance on the MIA data set are in order. ${ }^{6}$ First, while our sample is fairly large, it is still just a sample of IGOs and certainly not the whole population. This means that we are likely to underestimate institutional complexity because our analysis misses overlap between IGOs included in the sample and those that are not. A thorough assessment of institutional overlap would require information on the full population of IGOs and other international institutions in a given realm. Second, our sample includes the more authoritative IGOs, even if to a varying degree, that exist in world politics and this may affect our description of the phenomenon. Specifically, it is possible that a focus on these IGOs, compared to more 'representative' ones, will again lead us to underestimate overlap, perhaps because the prominent role that these IGOs play in their respective governance domains and world regions is likely to have discouraged the formation of other IGOs with similar policy competencies.

Third, our focus on formal IGOs leaves a range of other international institutions, such as private international institutions and informal IGOs, below our "threshold of "organizationhood" (Klabbers 2016: 135), and outside the realm of study. Again, this is likely to lead us to underestimate the level of overlap that actually exists in global governance since we do not capture the overlap that might exist with these other arrangements and the IGOs in our sample. Finally, MIA operates with a broad conceptualization of policy areas that categorizes some IGOs as falling into the same policy area, which, on closer inspection, turn out to be rather distinct. A more fine-grained definition of policy competency would reduce the incidence and extent of overlap that we observe. This bears on a more general point - the definition of policy overlap - to which we return in the conclusion. In sum, the specific features of the MIA dataset produce results that lead to an underestimation of complexity on some dimensions and an overestimation of overlap on others.

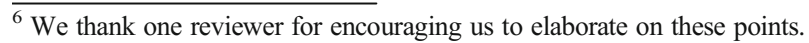




\subsection{Dyadic MEPOS}

Using Dyadic MEPOS to analyze IGO overlap in the MIA dataset, several observations stand out. A first key finding is that institutional overlap among important IGOs around the world has steadily increased over time. Specifically, our measure increased twofold from about 0.01 in 1970 to about 0.02 in 2014, bolstering existing claims that institutional overlap in global governance has grown significantly. While these values may appear low, they are not surprising given that many IGOs in the sample do not overlap on either membership or policy competencies (or both) with other IGOs, and thus score zero on Dyadic MEPOS. In fact, about $60 \%$ of the sample fall into this category.

This increase is driven largely by policy expansion rather than by growing membership. As Fig. 3 shows, the ratio of overlapping members to the total dyadic membership has remained fairly constant over the last four decades, hovering around $0.15{ }^{7}$ The equivalent ratio for policy competency, by contrast, jumped by about $80 \%$ in the same time period (from 0.10 to 0.18 ), reflecting the fact that policy expansion in an increasingly dense organizational space drives policy overlap upward. Further disaggregation according to the type of IGOs suggests that this distinction is especially pronounced for pairs of general purpose IGOs, for which the ratio of overlapping membership remains rather constant (0.03-0.04), but the ratio of policy competency overlap increased from 0.26 in 1970 to 0.46 in 2014. This reflects the internal logic of general purpose IGOs, which address the transnational problems that confront a given community, starting with a limited set of policies and expanding their scope over time as new problems emerge (Hooghe et al. 2019, Chapter 5). For task specific IGOs, both ratios appear to increase over time, but again more dramatically with respect to overlapping policy competencies.

To illustrate these dynamics, we examine dyads that score high on MEPOS and have received attention in the literature on governance complexity. One such case is the overlap between the World Intellectual Property Organization (WIPO) and the WTO. As several studies have noted, both IGOs deal with international trade and have overlapping, and to some extent competing, rules with respect to intellectual property rights (Abbott 2000; Helfer 2004; Gehring and Faude 2014). This overlap intensified in the 1990s with the conclusion of the Agreement on Trade-Related Aspects of Intellectual Property Rights (TRIPS) within the WTO, and then again in 2007, when WIPO adopted a development agenda. As Gehring and Faude, who see the two IGOs as having settled on a productive division of labor, pointed out (2014: 488-489), with the WTO's increased prominence in relation to intellectual property, WIPO expanded into new policy areas, such as development (also within the competency of the WTO). The value on Dyadic MEPOS nicely illustrates these developments: it increased from 0.20 in 1995 to 0.54 in 2014, making it the sixth highest in the entire dataset. Consistent with the general trend, this is mostly a result of WIPO's expansion of policy competencies and, to a lesser extent, growing WTO membership.

\footnotetext{
7 This is especially surprising given the growing number of states in the system during the Cold War and the positive correlation between the number of states and the number of IGOs (Pevehouse et al. 2020). This result may emanate from the limited number of IGOs in the sample or the lower growth rate of state creation after 1970.
} 


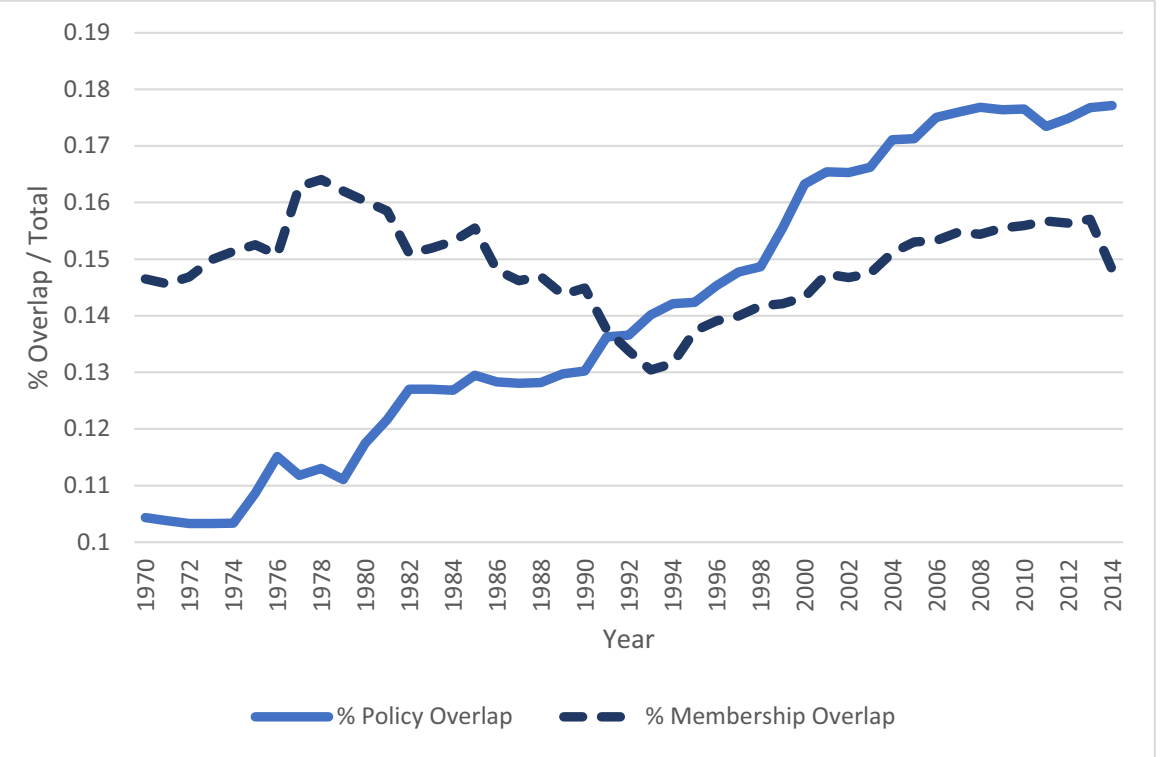

Fig. 3 Ratio of Overlapping Policy Competencies and Membership Overlap to Total Dyadic Values

A second illuminating example are three prominent IGOs that aim to advance human rights and democracy in Europe: the CoE, the Organization of Security and Cooperation in Europe (OSCE), and the EU. Several scholars have noted the growing overlap in their mandates, their efforts to coordinate human rights policies (or not), and the repercussions for their ability to advance their stated goals (Brosig 2010; Gawrich 2017). Our measure reflects this reality. Dyadic MEPOS for the CoE/OSCE pair increased from 0.13 in 1989 to 0.65 from 2007 onwards, the fourth highest value in the dataset. This was mostly a result of growing overlap in policy areas such as education, justice, and foreign policy, which soared from 0.2 in 1989 to 0.75 in 2007 (the corresponding values for membership overlap are 0.67 and 0.85). Dyadic MEPOS has also increased for the EU/CoE and EU/OSCE pairs, from 0.09 in 1989 to 0.16 in 2014 and from 0.07 in 1989 to 0.14 in 2014, respectively. These notable upsurges are indicative of the growing similarity between these IGOs' activities, not least in the areas of human rights protection, democracy promotion, and humanitarian aid, all embraced by the EU in 1999.

Another important finding is that the highest institutional overlap involves pairs of task specific rather than general purpose IGOs, as is apparent in Table A1 in the Appendix. This makes sense because these organizations tend to be global, generating high overlap scores on membership, while addressing a limited number of policies, leading to a small denominator and thus to a relatively higher overlap score on policy competency. With 151 overlapping states out of 185 that are members of both IGOs, and two overlapping policy areas out of three covered by these IGOs, the WTO/WIPO dyad exemplifies this reality. In contrast, as already mentioned, general purpose IGOs tend to be community-oriented, and thereby less malleable to various overlapping configurations than specific transnational problems around which task specific IGOs tend to form. The lower values for the EU/CoE pair, both of which are general purpose 
IGOs, are consistent with this expectation. Indeed, the average Dyadic MEPOS for pairs of task specific IGOs is twice as high as pairs of general purpose IGOs: 0.025 versus 0.012 respectively. At the same time, the standard deviation is also twice as high for pairs of task specific IGOs, 0.071, compared to 0.035 for general purpose IGO dyads. These statistics indicate that task specific pairs tend to have either high or low degrees of overlap, while the distribution is more 'normal' for general purpose IGOs.

\subsection{Accounting for the centrality of policy competencies in MEPOS}

So far, we have weighed all policy competencies equally when calculating IGO overlap. This may be an undue simplification. For example, some scholars argue that an IGO's behavior depends on whether overlap occurs in areas that the organization views as a core competency defining its raison d'etre or whether it affects more peripheral issue areas (Galbreath and Gebhard 2010). Brosig (2010), for example, argues that overlap in peripheral competencies is likely to produce inter-IGO cooperation, but that overlap in core competencies is likely to result in a division of labor between them. To account for this idea, we draw on Hooghe et al.'s (2019) distinction between core and flanking policies introduced above. ${ }^{8}$

One way to account for the relative salience of various issue areas is to include only core policy competencies in the calculation of Dyadic MEPOS. The mean for this variable, Dyadic MEPOS Core, is only 0.008, which is about half the value of the baseline measure. This is to be expected, of course, as overlap in flanking policy competencies is excluded. In particular, in contrast to the baseline measure, there is little temporal change in the mean value of overlapping policy competencies for pairs of task specific IGOs. This is probably due to the tendency of such IGOs to begin with a small number of core policy areas and to add flanking competencies later.

More importantly, switching to this measure can have notable effects on how one judges the relative overlap of different IGO pairs, as some obtain a higher value on MEPOS, while others score lower. Revisiting the WIPO/WTO pair, with a value of 0.81 in 2014 , the measure based only on core competencies is much higher than the one that takes into account flanking ones (0.54). That is because trade is the exclusive core competency of both IGOs, but competition is a flanking competency only for the WTO (and development is a flanking competency for both IGOs). The higher value on Dyadic MEPOS Core reflects qualitative research that underscores international trade as the main area around which the two IGOs interact (Helfer 2004; Gehring and Faude 2014). The CoE/OSCE dyad offers a contrasting example. Dyadic MEPOS Core is much lower than the baseline measure, 0.28 and 0.64 respectively. That is because they overlap on one core competency (human rights) but diverge on others (culture for the $\mathrm{CoE}$ and military cooperation for the OSCE). This reality facilitated a division of labor in the promotion of human rights (Brosig 2010), while simultaneously allowing the two IGOs to advance separate objectives in core competencies that do not overlap.

As a middle ground between these two poles, one could include all policy areas addressed by the overlapping IGOs but assign greater weight to core competencies. For example, an overlap of two core competencies scores 1, an overlap of a core competency and a flanking competency scores 0.75 , and an overlap of two flanking

\footnotetext{
${ }^{8}$ One could pursue a similar idea with regard to membership, for example by weighing members according to their economic or military power.
} 
competencies scores 0.5 (with zero for no overlap). To match the denominator to the numerator, the summation of policy competencies also accounts for these weights. This measure, labeled Dyadic MEPOS Weighted, produces higher values for IGO pairs that overlap on core policy competencies, but lower values for those that overlap on flanking competencies. Thus, the value for the WTO/WIPO dyad on this measure in 2014 is 0.61 , which is higher than the baseline measure (0.54) but lower than Dyadic MEPOS Core (0.81). Conversely, the value for the CoE/OSCE dyad on this measure in 2014 is also 0.61 , which is lower than the baseline measure $(0.64)$ but higher than Dyadic MEPOS Core (0.28).

To be clear, we consider all three versions of Dyadic MEPOS to be equally valid and believe that one should select the one that best fits the research goals and context. From a theoretical perspective, this may depend on expectations with respect to the consequences of overlap on core versus flanking policy competences. Insofar as such expectations diverge (Brosig 2010, 2011), the measures that only take into account core competency or assign different weights to core and flanking ones may be more appropriate. From an empirical viewpoint, however, such fine-grained measures require one to determine the centrality of various policy competencies to the international institutions under investigation. Assigning such labels may be contested and challenging, especially for a large number of institutions, as pointed out earlier.

\subsection{IGO overlap within policy-specific complexes}

Thus far, the analysis has only examined the relationships between pairs of IGOs. Given our interest in broader global governance complexes, we can use the average Dyadic MEPOS of several IGO dyads to gauge the institutional complexity of a particular policy area ${ }^{9}$ or a geographical region (keeping in mind that such dyads can still score zero on MEPOS if they do not overlap with respect to membership and/or policy competency). As an illustration, the WTO and WIPO are, of course, not the only IGOs tackling international trade. In fact, forty-five IGOs in the MIA dataset had either core or flanking competency with respect to this policy area, in some or all years. Moreover, as reported in Table A2 in the Appendix, with approximately $27 \%$ of the observations in the dataset in which both IGOs deal with trade, this policy area has the highest potential for overlap (which materializes only if accompanied by overlapping membership).

The average Dyadic MEPOS for all the IGO pairs that deal with trade is comparatively low, at around 0.015, and this value remains rather constant from 1970 to 2014. These observations may seem surprising considering the widely held perception that global trade governance is highly complex, and increasingly so; however, we maintain that they are actually revealing. Many IGOs that deal with trade aspire to advance regional economic interdependence and therefore have a regional rather than global membership (Haftel 2013). As the number of REOs has increased over the last few decades, their lower propensity for membership overlap has worked to offset the growing institutional density. This reality comports with the observation that regional

\footnotetext{
${ }^{9}$ One could repeat this exercise for core competencies only, or with the measure that assigns different weights to core and flanking policy competencies.
} 


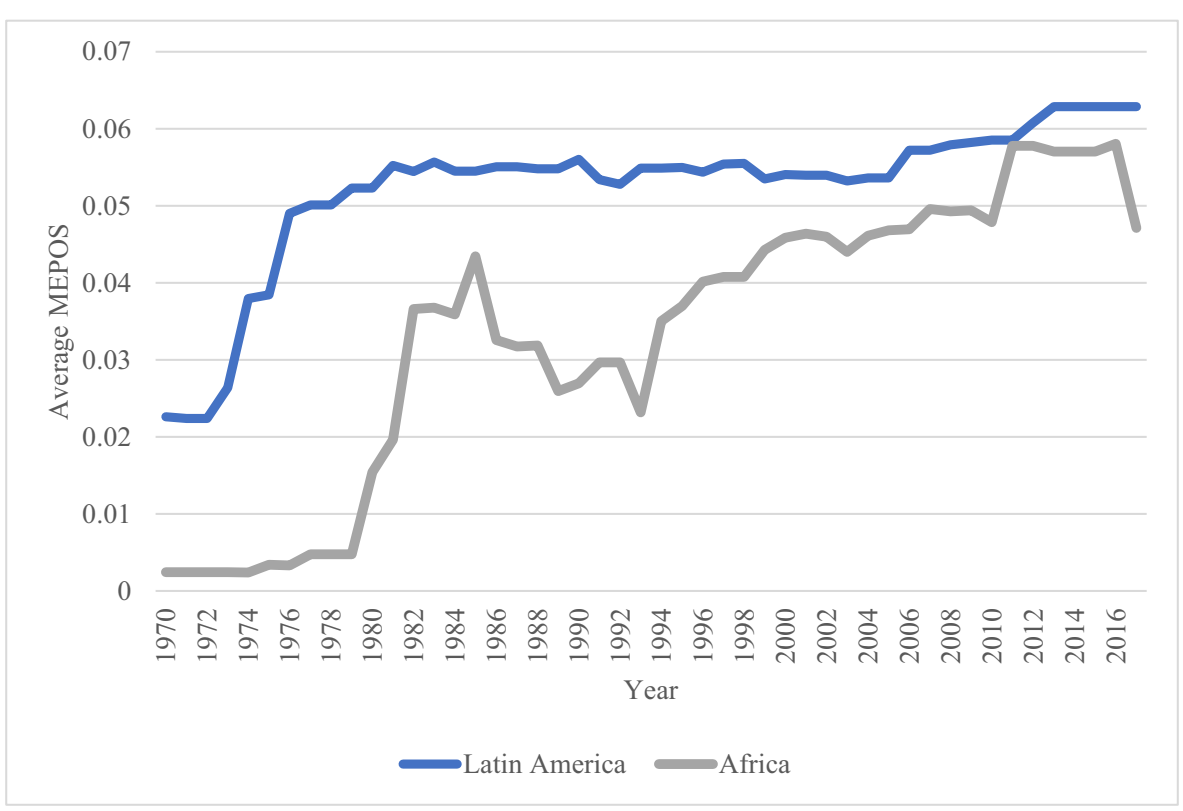

Fig. 4 Average Dyadic MEPOS of REO Dyads in Latin America and Africa, 1970-2017

IGOs, which tend to be community-based and general purpose institutions, produce lower degrees of overlap compared to global task specific IGOs.

Nevertheless, we do observe growing levels of overlap within specific macroregions. As an illustration, we calculate the average Dyadic MEPOS for eight and eleven REOs in Latina America and Africa, respectively, available in the MIA dataset. As Fig. 4 shows, the value on this variable has increased from very low levels in the 1970 s to about 0.05 in the 2010s in both regions (compared to 0.015 for all IGOs in the sample dealing with trade). This is consistent with qualitative work that has documented and analyzed the growing complexity of regional economic governance in these two continents, which largely examines formal IGOs (on Africa, see, for example, Brosig 2010; on Latin America, see Gómez-Mera 2015; Weiffen et al. 2013).

As already mentioned, the empirical focus on IGOs has its limits. In the area of trade, much of the growing governance complexity evolved through hundreds of preferential trade agreements (PTAs) rather than IGOs, at least since the 1990s. This development led scholars to describe the network of overlapping PTAs as a "spaghetti bowl" and "termites in the trading system" (Bhagwati 2008). Thus, a more complete and accurate depiction of global trade governance requires taking diverse institutional forms into account. Nevertheless, we emphasize that the prevalence of stand-alone agreements varies a great deal, not only across policy areas but also across geographical regions. For example, PTAs are much more common in Latin America than in Africa. This reality underscores the need to carefully consider and map all the relevant institutions before calculating overlap for a given global or regional governance complex. 


\subsection{Directed and monadic MEPOS}

Applying Directed MEPOS to the MIA dataset, the average for the entire sample is 0.063 , four times higher than the baseline measure; this is as expected. Here, several IGOs that are fully nested within their peers, with respect to both membership and policy competencies, score one on this variable. In Africa, for example, COMESA is fully nested within the AU, and SACU is fully nested within the SADC (and the AU), another reflection of the institutional density on this continent. With respect to global IGOs, several task specific IGOs, such as the International Labor Organization and the Interpol, are, unsurprisingly, fully nested within the UN. In line with previous results, the average Directed MEPOS is higher for dyads of task specific (0.08) than for general purpose IGOs (0.05).

As discussed above, Directed MEPOS can be averaged across more than one peer institution, thereby producing Monadic MEPOS. Given the incomplete sample of IGOs, it may be more fruitful to examine this variable with respect to a particular policy competency. Considering the relatively good coverage of IGOs that address trade, we use it to illustrate this measure. Out of the forty-six IGOs in our sample that have trade as either a core or a flanking competency, WIPO scores the highest on Monadic MEPOS (vis-à-vis the remaining forty-five IGOs), with 0.14. Several general purpose REOs, such as the Commonwealth of Independent States (CIS), ASEAN, and the Economic Community of Western African States, exemplify IGOs that score relatively low on this measure. With a value of 0.07 , the WTO is ranked only fourteenth. That is mostly because it tackles more non-trade policy areas than other IGOs, such as WIPO. Be that as it may, these values are mostly illustrative and should be interpreted with caution. An accurate assessment of governance complexity based on Monadic MEPOS would require information on a much larger number of trade agreements and other institutions.

\section{Implications for research on global governance complexes and avenues for future research}

Our descriptive analysis of IGO overlap in global governance - a first, but important, step towards a systematic analysis of this phenomenon - has implications for several important literatures, to which we now turn. Our analysis raises questions about possible explanations for the marked variation in institutional overlap, as well as its implications for cooperation and conflict in world politics. Thus, future analyses could treat our proposed measures either as a dependent or as an independent variable. We discuss implications for research on institutional design and evolution, legitimacy and legitimation, and effectiveness and performance.

\subsection{Institutional design and evolution}

Institutional overlap is a relational characteristic that concerns two or more institutions; such relational features have been neglected in the quantitative literature on IGO design and evolution. Over the past decade or so, research has sought to conceptualize and measure various 'internal' features of international institutions, such as the degree of 
independence from member states and institutionalization (Haftel and Thompson 2006; Haftel 2013), informality (Vabulas and Snidal 2013), policy competency (Panke et al. 2020), authority (Hooghe et al. 2017) and design (Balsiger and Prys 2016; Koremenos 2016). Our measures and descriptive analyses complement these path-breaking efforts with a focus on the relationships between different institutions. Such research has a different ontological starting point than the research mentioned above: it focuses on the relational aspects of units of analysis where "configurations of ties - recurrent sociocultural interaction - between social aggregates of various sorts and their component parts [are] the building blocks of social analysis" (Jackson and Nexon 1999: 291-92). This ontological stance not only underpins research on regime complexity and institutional overlap, but also other recent work on diffusion, ties, and networks (Sommerer and Tallberg 2019; Lenz and Burilkov 2017; Hafner-Burton et al. 2009). Our measures contribute to quantitative research on IGO design by offering systematic assessments of relational, as opposed to unit-based features of institutions.

This relational perspective is useful in addressing questions about both the sources and consequences of institutional overlap in global governance. Regarding the former, much of the literature on regime complexity focuses on cross-institutional strategies of states. For example, scholars have argued that for cases as diverse as Brazil's initiative to create the Union of South American Nations (UNASUR) as a counter-weight to the OAS (Weiffen et al. 2013), the BRICS' countries establishment of the NDB and China's drive to create the AIIB as a counter-weight to the WB (Roberts et al. 2018; Stephen 2020), a powerful state's dissatisfaction with the institutional status quo leads to the creation of new or the expansion of existing institutions that overlap with (other) existing ones. While those studies are based on a detailed empirical analysis, our study challenges such arguments to engage with variation across policy-specific and geographical governance complexes more systematically. Combining quantitative measures of states' dissatisfaction with the institutional status quo with our measures of institutional overlap would allow scholars to undertake such endeavors.

However, our analysis also suggests that scholars should move beyond a focus on states' cross-institutional strategies that center on questions of IGO membership. As we have shown, the marked increase in institutional overlap between 1970 and 2014 was driven primarily by the expansion of existing IGOs' policy competencies rather than by growing membership. This suggests that scholars should complement their focus on state strategies with an inquiry into the role of a wider set of actors who drive policy expansion. This would provide potentially fruitful links to the literature on bureaucracies and mission creep, which shows that IGO staff are important actors in the design of new and the expansion of existing IGOs (Haas 1958; Johnson 2014). For example, Pollack (1994) argues that 'policy entrepreneurship' by the European Commission played a key role in expanding the European Community's agenda to new policy areas. A pivotal consequence of such 'mission creep' (Pollack 1994) is that institutional overlap with other IGOs grows, as shown by the aforementioned example of the $\mathrm{CoE}$, the EU, and the OSCE. Do arguments such as these generalize to a powerful explanation of growing governance complexity? It seems that the literatures on governance complexity, on the one hand, and on IGO bureaucracies and mission creep, on the other, would benefit from closer integration in order to answer questions related to the sources of governance complexity. 
Regarding the consequences of governance complexity for institutional design, recent research suggests that IGO design depends on the institutional environment in which an IGO is embedded (Copelovitch and Putnam 2014; Haftel and Hofmann 2019; Lenz and Burilkov 2017; Reinsberg and Westerwinter 2019), and that this environment increasingly includes institutional overlap between distinct international institutions. For example, Hofmann (2011) argues, with reference to security in Europe, "Once institutional overlap exists, it becomes a crucial independent variable explaining [...] the development of international institutions occupying the same policy domain." To what extent do arguments such as these withstand systematic scrutiny? Specifically, do higher degrees of institutional overlap explain a larger share of the variation in the design of international institutions? Are there thresholds to such impact? Moreover, would we expect institutional overlap, given the exchange that it enables, to induce convergence in the design of overlapping institutions, as the literature on diffusion suggests (Sommerer and Tallberg 2019)? Or, alternatively, might overlap lead to a polarization in the design of overlapping institutions due to processes of competition and rivalry, as the literature on organizational ecology tends to expect (Hannan and Freeman 1989)? These questions emerge from a more systematic understanding of patterns of institutional overlap, but our measures also help scholars to answer them.

\subsection{Legitimacy and legitimation}

Institutional overlap implies legitimate, yet competing, claims to govern a specific policy area, and this conceptualization suggests potential points of engagements between the literature on institutional overlap and that on legitimacy and legitimation in global governance (Abbott et al. 2016). Legitimacy denotes a voluntary recognition of an organization's right to rule, while legitimation refers to activities that are geared towards enhancing an institution's legitimacy (Weber 1978; Tallberg and Zürn 2019). Beyond the agreement that legitimacy is important for political rule, scholars have vigorously debated the sources of legitimacy judgements and legitimation strategies, as well as their consequences for global governance - debates to which our measures can contribute.

These debates point to another potential source of institutional overlap in global governance that existing research on the topic has largely neglected. We may conceive institutional overlap as emerging and evolving as a function of the 'battles for legitimacy' (Wajner 2019), by which each overlapping institution seeks to convince stakeholders that its claim to govern a policy area is more legitimate than that of its 'rival.' Overlap may be more likely to ensue or increase, for example, when the legitimacy of an institution is low, since illegitimate institutions may find it harder to defend their turf against encroachment by other institutions (Zelli 2018: 176). Along these lines, Weiffen et al. (2013) showed that the delegitimation of the OAS preceded the creation of the overlapping UNASUR, which is seen as being more legitimate because it excludes the United States. Do arguments such as these generalize beyond specific cases? Concretely, does variation in legitimacy perceptions explain variation in institutional overlap? Are higher levels of overlap in the area of environmental protection or human rights, compared to trade or energy, attributable to the belief among relevant stakeholders that the former policy areas are more legitimately addressed through multilateral cooperation than the latter? Or is the opposite true: beliefs that a policy is 
legitimately addressed at the international level induces lower degrees of overlap among different institutions concerned with this issue? Similarly, does multilateral cooperation enjoy a higher degree of legitimacy in Africa when compared to Latin America, given their respective degrees of institutional overlap?

In turn, institutional overlap in global governance may also have consequences for the legitimacy perceptions and legitimation strategies of institutions. Legitimacy is achieved when an institution's key features - such as its procedures, purpose or performance - align with the norms and beliefs of important organizational stakeholders (Beetham 1991). However, recent research on the cognitive sources of legitimacy suggests that legitimacy judgments are comparative in nature; that is, stakeholders assess the legitimacy of an institution not against an ideal situation in which organizational features and underlying norms are in perfect alignment, but against a referent organization that is available in an organization's environment (Lenz et al. 2019).

Consequently, legitimacy perceptions are not specific to individual institutions, and instead depend heavily on who that referent is. For example, an extensive body of research shows that assessments of the legitimacy of international organizations depend on the trust that citizens hold in domestic institutions (Armingeon and Ceka 2014; Dellmuth and Tallberg 2020). So far, this literature has considered easily available and particularly high-profile institutions as relevant referents to assess the legitimacy of IGOs, but the growing overlap among them may increasingly provide other important reference points. In this vein, our measures of institutional overlap could be used to explain the legitimacy perceptions of IGOs and other institutions in global governance.

Relatedly, overlap is likely to affect the process of legitimation. When an institution enjoys a monopoly in governing a specific policy area, its legitimacy claims are likely to center on claiming that its core characteristics are indeed in line with stakeholders' normative beliefs, that it merits being seen legitimate 'on its own terms.' When overlap emerges, however, the struggle for legitimacy is likely to reflect this altered institutional context. Specifically, institutions now need to convince their stakeholders that they are more legitimate than their potential competitor(s) to govern a particular policy area. As a result, we may hypothesize that institutions either seek a more explicit differentiation of their legitimacy claims from those of overlapping institutions (competition), or that they aim for the collective legitimation of governance complexes, as opposed to individual institutions (coordination). The measures presented in this article, coupled with systemic analyses of institutional legitimacy and legitimation, will allow scholars to have a better grasp of the relationship between the complexity of global governance and the legitimacy of specific institutions as well as entire complexes.

\subsection{Effectiveness and performance}

A vibrant community of scholars has studied the effectiveness and performance of IGOs, and of international institutions more broadly. Much of this research has focused on factors intrinsic to the specific IGO in question, such as its policy autonomy, bureaucratic dysfunction, conflicting mandates, and rent-seeking by public officials (see, for example, Barnett and Finnemore 2004; Gutner and Thompson 2010; Lall 2017; Weaver 2008). Recent research on governance complexity, in turn, is interested in the consequences of this phenomenon for institutional performance. Whereas most 
analyses expect overlap to undermine performance due to conflicting rules and norms (Alter and Meunier 2009; Raustiala and Victor 2004), others expect overlap to have little effect on performance, or even to enhance it, due to processes of inter-institutional coordination (Eilstrup-Sangiovanni 2021; Gehring and Faude 2014; Pratt 2018). With only a few exceptions, this research is based on individual case studies.

Our measures could complement these studies by providing a basis for a systematic analysis of institutional performance across time and space. In particular, the monadic measure could be used as an independent variable to examine its effect on performance, with the individual institution as the unit of analysis. For example, are institutions integrated into a dense network of overlapping institutions more or less likely to 'zombie-fy' or to dissolve (Gray 2018; Eilstrup-Sangiovanni 2020)? Or does institutional overlap worsen implementation problems, an argument that Gómez-Mera (2015) advanced in relation to trade governance in the Americas? Conversely, are overlapping institutions more likely to display a high performance, perhaps due to their central position in a network of overlapping institutions that affords them with structural power in a specific policy domain (Winecoff 2020)?

The proposed measures also allow researchers to test hypotheses regarding the impact of institutional performance on overlap. Akin to the expectations regarding the impact of legitimacy on overlap, we may expect that poor performance will eventually lead member states - maybe after failed attempts to reform existing institutions in order to mitigate performance problems - to create new institutions with overlapping policy competencies and memberships. Poorly performing institutions may be expected to find it more difficult to fend off attempts to create rivalling institutions, while such institutions are more vulnerable to cross-institutional strategies by states. A case in point was the ailing Kyoto Protocol in the early 2000 s, which led to a proliferation of alternative forums and trans-governmental networks that promised better outcomes (Zelli 2018: 181). Conversely, we may expect international institutions that perform well to be less threatened by institutional overlap. Such institutions may find it easier to defend their policy turf against encroachment by other institutions by reducing functional motives of states for the creation of additional institutions and by deterring other institutions from entering the same governance domain. Do hypotheses such as these stand up to systematic empirical scrutiny? Researchers could use both the monadic and dyadic measures to examine such theoretical expectations.

\section{Conclusion}

The increasing number and density of global governance complexes is accompanied by growing scholarly interest and a burgeoning body of literature on this phenomenon. Nevertheless, much of this research emphasizes conceptual and theoretical advancements, at the expense of systematic empirical inquiry. This reality emanates, at least in part, from a dearth of reliable measures and data on key concepts. As the research program on global governance complexity matures, however, the time is ripe for greater attention to empirical questions and measurement.

This article takes an important step in this direction by making two contributions. First, it proposes new measures that gauge the extent of institutional overlap, which is based on the interaction of membership and policy competencies. We demonstrate 
that these measures can be used not only with respect to any two international institutions, but also for single institutions in the context of policy-specific or geographically demarcated governance complexes. We also point out that values on these measures are sensitive to coding decisions with respect to membership and policy competency.

Second, we illustrate the utility of these measures by applying them to a recent dataset on formal IGOs. This analysis underscores the marked variation in the degree of overlap across IGO pairs, time, type of IGO, geographical regions, and policy areas. In one interesting example, we find that the growing institutional overlap is driven much more by the expansion of policy competencies of existing IGOs than by growing state membership, and that this is especially apparent for pairs of general purpose IGOs, which tend to expand their policy scope over time. Nevertheless, we also find that several pairs of task specific IGOs score very high on our measures, because they have close to universal membership and a rather narrow policy scope. As the WIPO/WTO and $\mathrm{CoE} / \mathrm{OSCE}$ examples suggest, this may lead to a more intense interaction between such IGOs.

To make the most of the measures developed in this article, we should move beyond descriptive analyses and utilize them to address questions that are of interest to scholars of global governance. As a first step in this direction, we point to three research areas in which we believe they could come in handy: institutional design and evolution, institutional legitimacy and legitimation, and institutional performance. While these research areas are still tentative, following up on them may shed new light on global governance complexes. As we have already emphasized, we used the MIA dataset for illustrative purposes. Answering the questions posed in the previous section systematically also requires more comprehensive data on the various institutions composing governance complexes. We believe that mapping such complexity, perhaps starting with a specific issue area and/or a geographical region, is a fruitful avenue for further research.

Supplementary Information The online version contains supplementary material available at https://doi.org/ 10.1007/s11558-021-09415-3.

Open Access This article is licensed under a Creative Commons Attribution 4.0 International License, which permits use, sharing, adaptation, distribution and reproduction in any medium or format, as long as you give appropriate credit to the original author(s) and the source, provide a link to the Creative Commons licence, and indicate if changes were made. The images or other third party material in this article are included in the article's Creative Commons licence, unless indicated otherwise in a credit line to the material. If material is not included in the article's Creative Commons licence and your intended use is not permitted by statutory regulation or exceeds the permitted use, you will need to obtain permission directly from the copyright holder. To view a copy of this licence, visit http://creativecommons.org/licenses/by/4.0/.

\section{References}

Abbott, F. M. (2000). Distributed governance at the WTO-WIPO: An evolving model for open-architecture integrated governance. Journal of International Economic Law, 3(1), 63-81.

Abbott, K. W. (2012). The transnational regime complex for climate change. Environment and Planning C: Government and Policy, 30(4), 571-590.

Abbott, K. W., \& Faude, B. (2021). Hybrid institutional complexes in global governance. Unpublished ms. 
Abbott, K. W., Keohane, R. O., Moravcsik, S., \& A. M., \& Snidal, D. (2000). The concept of legalization. International Organization, 54(3), 401-419.

Abbott, K. W., Genschel, P., Snidal, D., \& Zangl, B. (Eds.). (2015). International organizations as orchestrators. Cambridge: Cambridge University Press.

Abbott, K. W., Green, J. F., \& Keohane, R. O. (2016). Organizational ecology and institutional change in global governance. International Organization, 70(2), 247-277.

Alter, K. J., \& Raustiala, K. (2018). The rise of international regime complexity. Annual Review of Law and Social Science, 14, 329-349.

Alter, K. J., \& Sophie Meunier, S. (2009). The politics of regime complexity. Perspectives on Politics, 7(1), $13-24$.

Armingeon, K., \& Ceka, B. (2014). The loss of trust in the European Union during the great recession since 2007: The role of heuristics from the national political system. European Union Politics, 15(1), 82-107.

Balsiger, J., \& Prys, M. (2016). Regional agreements in international environmental politics. International Environmental Agreements: Politics, Law and Economics, 16(2), 239-260.

Barnett, M., \& Finnemore, M. (2004). Rules for the world: International organizations in global politics. Ithaca: Cornell University Press.

Beetham, D. (1991). The legitimation of power. Macmillan International Higher Education.

Betts, A. (2010). The refugee regime complex. Refugee Survey Quarterly, 29(1), 12-37.

Betts, A. (2013). Regime complexity and international organizations: UNHCR as a challenged institution. Global Governance, 19(1), 69-81.

Bhagwati, J. (2008). Termites in the trading system: How preferential agreements undermine free trade. Oxford: Oxford University Press.

Brosig, M. (2010). Governance between international institutions: Analysing interaction modes between the EU, the Council of Europe and the OSCE. In D. Galbreath \& C. Gebhard (Eds.), Cooperation or conflict? Problematizing organizational overlap in Europe (pp. 29-58). Aldershot: Ashgate.

Brosig, M. (2011). Overlap and interplay between international organisations: Theories and approaches. South African Journal of International Affairs, 18(2), 147-167.

Copelovitch, M. S., \& Putnam, T. L. (2014). Design in context: Existing international agreements and new cooperation. International Organization, 68(2), 471-493.

Davis, C. (2009). Overlapping institutions in trade policy. Perspectives on Politics, 7(1), 25-31.

Dellmuth, L. M., \& Tallberg, J. (2020). Elite communication and the popular legitimacy of international organizations. British Journal of Political Science, 1-22. https://doi.org/10.1017/S0007123419000620.

Eilstrup-Sangiovanni, M. (2020). Death of international organizations: Organizational ecology of intergovernmental organizations, 1815-2015. The Review of International Organizations, 15, 339-370.

Eilstrup-Sangiovanni, M. (2021). 'Ordering' global governance complexes: The evolution of the governance complex for international civil aviation. The Review of International Organizations. https://doi.org/10. 17863/CAM.61028.

Eilstrup-Sangiovanni, M., \& Westerwinter, O. (2020). Variation and consequences of global governance complexity. Unpublished ms.

Faude, B., \& Abbott, K. (2020). Choosing low-cost institutions in global governance. International Theory, 130. https://doi.org/10.1017/S1752971920000202.

Galbreath, D., \& Gebhard, C. (Eds.). (2010). Cooperation or conflict? Problematizing organizational overlap in Europe. Aldershot: Ashgate.

Gawrich, A. (2017). Inter-organizational relations in the field of democratisation: Cooperation or delegation? The European Union, the OSCE, and the Council of Europe. In R. Biermann \& J. A. Koops (Eds.), Palgrave handbook of inter-organizational relations in world politics (pp. 527-546). London: Palgrave Macmillan.

Gehring, T., \& Faude, B. (2014). A theory of emerging order within institutional complexes: How competition among regulatory international institutions leads to institutional adaptation and division of labor. The Review of International Organizations, 9(4), 471-498.

Gómez-Mera, L. (2015). International regime complexity and regional governance: Evidence from the Americas. Global Governance, 21(1), 19-42.

Gray, J. (2018). Life, death, or zombie? The vitality of international organizations. International Studies Quarterly, 62(1), 1-13.

Gutner, T., \& Thompson, A. (2010). The politics of IO performance: A framework. The Review of International Organizations, 5(3), 227-248.

Haas, E. B. (1958). The uniting of Europe: Political, social, and economical forces, 1950-1957. Stanford: Stanford University Press. 
Hafner-Burton, E., Kahler, M., \& Montgomery, A. H. (2009). Network analysis for international relations. International Organization, 63(3), 559-592.

Haftel, Y. Z. (2013). Commerce and institutions: Trade, scope, and the design of regional economic organizations. The Review of International Organizations, 8(3), 389-414.

Haftel, Y. Z., \& Hofmann, S. C. (2019). Rivalry and overlap: Why regional economic organizations encroach on security organizations. Journal of Conflict Resolution, 63(9), 2180-2206.

Haftel, Y. Z., \& Thompson, A. (2006). The independence of international organizations: Concept and applications. Journal of Conflict Resolution, 50(2), 253-275.

Hannan, M. T., \& Freeman, J. (1989). Organizational ecology. Cambridge: Harvard University Press.

Helfer, L. (2004). Regime shifting: The TRIPs agreement and the new dynamics of international intellectual property lawmaking. Yale Journal of International Law, 29(1), 1-83.

Henning, R. (2017). Tangled governance: International regime complexity, the troika, and the euro crisis. Oxford: Oxford University Press.

Hofmann, S. C. (2009). Overlapping institutions in the realm of international security: The case of NATO and ESDP. Perspectives on Politics, 7(1), 45-52.

Hofmann, S. C. (2011). Why institutional overlap matters: CSDP in the European security architecture. Journal of Common Market Studies, 49(1), 101-120.

Hofmann, S. C. (2019). The politics of overlapping organizations: Hostage-taking, forum-shopping and brokering. Journal of European Public Policy, 26(6), 883-905.

Hooghe, L., Marks, G., Lenz, T., Bezuijen, J., Ceka, B., \& Derderyan, D. (2017). Measuring international authority: A postfunctionalist theory of governance. Oxford: Oxford University Press.

Hooghe, L., Lenz, T., \& Marks, G. (2019). A theory of international organization. Oxford: Oxford University Press.

Jackson, P. T., \& Nexon, D. (1999). Relations before states: Substance, process and the study of world politics. European Journal of International Relations, 5(3), 291-332.

Johnson, T. (2014). Organizational progeny: Why governments are losing control over the proliferating structures of global governance. Oxford: Oxford University Press.

Jupille, J., Mattli, W., \& Snidal, D. (2013). Institutional choice and global commerce. Cambridge: Cambridge University Press.

Keohane, R. O., \& Victor, D. G. (2011). The regime complex for climate change. Perspectives on Politics, $9(1), 7-23$.

Klabbers, J. (2016). Formal intergovernmental organizations. In J. Katz Cogan, I. Hurd, \& I. Johnstone (Eds.), Oxford handbook of international organizations (pp. 133-151). Oxford: Oxford University Press.

Knill, C., Bayerlein, L., Enkler, J., \& Grohs, S. (2019). Bureaucratic influence and administrative styles in international organizations. The Review of International Organizations, 14, 83-106.

Koremenos, B. (2016). The continent of international law: Explaining agreement design. Cambridge: Cambridge University Press.

Lall, R. (2017). Beyond institutional design: Explaining the performance of international organizations. International Organization, 71(2), 245-280.

Lenz, T., \& Burilkov, A. (2017). Institutional pioneers in world politics: Regional institution building and the influence of the European Union. European Journal of International Relations, 23(3), 654-680.

Lenz, T., Burilkov, A., \& Viola, L. A. (2019). Legitimacy and the cognitive sources of international institutional change: The case of regional parliamentarization. International Studies Quarterly, 63(4), 1094-1107.

Lenz, T., Bezuijen, J., Hooghe, L., \& Marks, G. (2015). Patterns of international organization: Task specific vs. general purpose. Politische Vierteljahresschrift, 49, 131-156.

Lesage, D., \& Van de Graaf, T. (2013). Thriving in complexity? The OECD system's role in energy and taxation. Global Governance, 19(1), 83-92.

Morin, J.-F. (2020). Concentration despite competition: The organizational ecology of technical assistance providers. The Review of International Organizations, 15(1), 75-107.

Morse, J. C., \& Keohane, R. O. (2014). Contested multilateralism. The Review of Iinternational Organizations, 9(4), 385-412.

Orsini, A., Morin, J.-F., \& Young, O. (2013). Regime complexes: A buzz, a boom, or a boost for global governance? Global Governance, 19, 27-39.

Panke, D., \& Stapel, S. (2018). Exploring overlapping regionalism. Journal of International Relations and Development, 21(3), 635-662.

Panke, D., Stapel, S., \& Starkmann, A. (2020). Comparing regional organizations: Global dynamics and regional particularities. Bristol: Bristol University Press. 
Pevehouse, J. C. W., Nordstrom, T., McManus, R. W., \& Jamison, A. S. (2020). Tracking organizations in the world: The correlates of war IGO version 3.0 datasets. Journal of Peace Research, 57(3), 492-503.

Pierson, P. (1996). The path to European integration: A historical institutionalist analysis. Comparative Political Studies, 29(2), 123-163.

Pollack, M. (1994). Creeping competence: The expanding agenda of the European Community. Journal of Public Policy, 14(2), 95-145.

Pratt, T. (2018). Deference and hierarchy in international regime complexes. International Organization, 72(3), 561-590.

Raustiala, K., \& Victor, D. G. (2004). The regime complex for plant genetic resources. International Organization, 58(2), 277-309.

Reinsberg, B., \& Westerwinter, W. (2019). The global governance of international development: Documenting the rise of multi-stakeholder partnerships and identifying underlying theoretical explanations. The Review of International Organizations, 16(1), 59-94.

Roberts, C. A., Armijo, L. E., \& Katada, S. N. (2018). The BRICS and collective financial statecraft. Oxford: Oxford University Press.

Sommerer, T., \& Tallberg, J. (2019). Diffusion across international organizations: Connectivity and convergence. International Organization, 73(2), 399-433.

Stephen, M. (2020). China's new multilateral institutions: A framework and research agenda. International Studies Review. https://doi.org/10.1093/isr/viaa076.

Tallberg, J., \& Zürn, M. (2019). The legitimacy and legitimation of international organizations: Introduction and framework. The Review of International Organizations, 14, 581-606.

Urpelainen, J., \& Van de Graaf, T. (2014). Your place or mine? Institutional capture and the creation of overlapping international institutions. British Journal of Political Science, 45(4), 799-827.

Vabulas, F., \& Snidal, D. (2013). Organization without delegation: Informal intergovernmental organizations (IIGOs) and the spectrum of intergovernmental arrangements. The Review of International Organizations, $8(2), 193-220$.

Verdier, D. (2021). Bargaining strategies for governance complex games. The Review of International Organizations. https://doi.org/10.1007/s11558-020-09407-9.

Wajner, D. (2019). "Battling" for legitimacy: Analyzing performative contests in the Gaza flotilla paradigmatic case. International Studies Quarterly, 63(4), 1035-1050.

Weaver, C. (2008). Hypocrisy trap: The World Bank and the poverty of reform. Princeton: Princeton University Press.

Weber, M. (1978). Economy and society: An outline of interpretive sociology. Berkeley: University of California Press.

Weiffen, B., Wehner, L., \& Nolte, D. (2013). Overlapping regional security institutions in South America: The case of OAS and UNASUR. International Area Studies Review, 16(4), 370-389.

Westerwinter, O. (2021). Transnational public-private governance initiatives in world politics: Introducing a new dataset. The Review of International Organizations, 16, 137-174.

Winecoff, W. K. (2020). The persistent myth of lost hegemony, revisited: Structural power as a complex network phenomenon. European Journal of International Relations, 26, 209-252.

Zelli, F. (2018). Effects of legitimacy crises in complex global governance. In J. Tallberg, K. Bäckstrand, \& J. A. Scholte (Eds.), Legitimacy in global governance: Sources, processes, and consequences (pp. 169188). Oxford: Oxford University Press.

Publisher's note Springer Nature remains neutral with regard to jurisdictional claims in published maps and institutional affiliations. 


\section{Affiliations}

Yoram Z. Haftel ${ }^{1} \cdot$ Tobias Lenz ${ }^{2}$

$\triangle$ Yoram Z. Haftel

yoram.haftel@mail.huji.ac.il

Tobias Lenz

tobias.lenz@leuphana.de

1 Department of International Relations, The Hebrew University of Jerusalem, Jerusalem, Israel

2 Center for the Study of Democracy \& Institute of Political Science, Leuphana University Lüneburg, Lüneburg, Germany 